Resenha

\title{
A pesquisa social e a construção de um novo caminho para a segurança pública no Brasil
}

\author{
Social research and the construction of a new \\ path public security in Brazil
}

Alberto L. Kopittke*

Resenha de:

LIMA, Renato Sérgio de; RATTON, José Luiz; AZEVEDO, Rodrigo Ghiringhelli de (orgs.). Crime, polícia e justiça no Brasil. São Paulo: Contexto, 2014.

O livro Crime, polícia e justiça no Brasil é um marco na discussão sobre segurança pública no Brasil. A obra traz um resgate da produção das ciências sociais brasileiras ao longo das últimas duas décadas sobre a violência e aponta os desafios futuros para que nosso país possa construir um novo olhar sobre esse tema e encontrar novas formas de atuação do estado para sua prevenção. Ao reunir alguns dos pesquisadores que realizaram os mais profundos estudos sobre o tema no país, o livro é uma leitura obrigatória a todos que se dispunham a pensar de forma crítica a atual situação de violência e o sistema de crenças que sustenta um modelo de atuação do poder público, que não tem tido êxito ao longo dos últimos 50 anos.

Muito mais do que um manual tradicional, os seus 60 tópicos se apresentam de forma muito mais rica do que os verbetes isolados das antigas enciclopédias. Seus textos formam uma trama de conceitos e temas que perpassam conhecimentos transdisciplinares de História, Ciências Sociais,

\footnotetext{
* Bacharel em Direito e mestrando em Ciências Criminais pela Pucrs em Porto Alegre, RS, Brasil<albertopoa2012@gmail.com>.
} 
Antropologia, Psicologia Social, Direito, Criminologia, Gestão Pública, entre outros, os quais, antes de se contradizerem ou tentarem se anular em batalhas argumentativas, se enriquecem mutuamente a cada nova leitura, proporcionando um processo de reflexão profundo, crítico e complexo sobre o fenômeno da violência e da atuação dos diversos atores sociais sobre o tema.

A obra, organizada por três dos mais experientes pesquisadores da nova geração de cientistas sociais do Brasil, possui uma lógica interna que talvez não seja percebida num primeiro olhar, até porque opta por não se apresentar de forma esquemática e estanque: apresenta as grandes escolas de pensamento sobre o tema, um vasto conjunto de conceitos chaves para a compreensão da realidade brasileira, passando por temáticas específicas de grande relevância como violência e mulheres, violência e juventude, drogas, crime organizado, o papel da mídia, sistema prisional e polícias, chegando finalmente à apresentação de ferramentas e técnicas concretas de gestão das políticas públicas de segurança.

Em comum, os textos possuem a capacidade crítica, de identificar nos fenômenos sociais relacionados com a violência a manifestação de estruturas mais profundas e invisíveis, que se encondem muito abaixo da superfície do cotidiano e que não raro são sustentadas por complexas e antigas relações de poder (e portanto de exclusão) de nossa sociedade, que não raro resultam em formas de interpretar e agir no mundo que projetam preconceitos e estigmatizações, em processos que de tão naturalizados não são perceptíveis no dia a dia. Mais do que encontrar $a$ teoria explicativa definitiva, que tenha o condão mágico de explicar todos os fenômenos da realidade, esses estudos têm procurado explicitar dinâmicas patológicas que se retroalimentam dos seus próprios resultados negativos, numa espiral em que o próximo resultado negativo, serve como justificativa para aprofundar os mecanismos que o produziram.

Esse processo paradoxal que o discurso sobre a violência exacerba, resulta num maior empoderamento de determinadas estruturas burocráticas e numa sociedade cada vez mais tomada pelo pânico social, que aceita de bom grado qualquer proposta de redução de direitos e reduz o espaço de reflexão crítica. Trata-se de discurso atualmente hegemônico, que se sustenta em crenças reiteradas e disseminadas nos discursos e nas práticas nos mais diversos espaços e instituições, que vão de tribunais, parlamentos, universidades, organizações policiais, veículos de comunicação até conversas de bar, num ciclo incessante de autorreforço, onde outras formas de compreensão e propostas de ação diversas das atuais, são rapidamente refutadas e deslegitimadas. 
Aliás, o atual discurso sobre a violência no Brasil, em seu maniqueísmo simplista, possui fortes mecanismos de autodefesa. Ao sinal de qualquer questionamento ao seu sistema de verdades e sua lógica própria de interpretar o mundo, são disparadas estratégias argumentativas com vistas a associar o seu "adversário" ao outro lado da linha, ao lado daqueles que seriam os responsáveis por todos os males de violência e medo da sociedade. Na lógica da guerra, quem questiona está com o inimigo. Na lógica do corporativismo, quem questiona ofende a instituição. É esse muro que a obra busca superar através da qualidade de seus textos.

As buscas de compreensão empreendidas no livro estão numa perspectiva diversa daquelas que buscam explicar a violência com base em características individuais e também daquelas que se lançam nos labirintos jurídicos da política criminal, embora não desconheçam que estes são dois elementos de grande relevância da dinâmica social, mas que precisam ser compreendidos a partir de uma rede de relações inserida numa determinada realidade social, cultural e historicamente específica, no caso a brasileira.

É nessa realidade que Kant de Lima aponta que tem ficado evidente que “os agentes das instituições policiais e judiciais brasileiras não se regulam nem pela lei, nem pelas normas internas explícitas que produzem, mas por rotinas implícitas de comportamento, transmitidas tradicionalmente e não explícitas para o observador casual". Essa "tradição implícita" que permeia e fundamenta o comportamento e as crenças dos membros das forças de segurança pública no Brasil possui raízes profundas, que se estendem até a própria formação do Brasil colonial, na forma burocrático-cartorária da organização judiciária colonial portuguesa e que teve por consequência a formação de uma cultura reativa às formas de controle, baseada na inércia, na formação de lealdades pessoais verticais, na busca por vantagens particulares, num etos corporativo avesso à responsabilização dos agentes públicos. Dessa forma, o controle social que se materializa, segundo o autor, nas práticas burocráticas dos sistemas policial e judicial, não se encontra orientado para a consensualização dos fatos, mas para a busca de uma verdade formal, a ser prolatada pela autoridade judicial, sem fomentar o processo de escolha individual dos agentes públicos, o que provocaria um profundo abismo entre as regras escritas e as práticas profissionais, entre o saber ensinado durante a formação oficial e o saber prático reproduzido na rua, formando éticas próprias que só podem ser modificadas se devidamente compreendidas.

A relevância desse processo de formação da identidade profissional do policial também é sublinhada por Poncioni. Embora esse processo seja comum em todas as polícias do mundo, em razão das características de sua 
atividade, a autora destaca a presença de valores e crenças do militarismo como um acento específico da cultural institucional das polícias militares no Brasil. Esse processo se autorreforçaria ao longo do tempo em razão do monopólio das academias de polícia, que realizam de forma "fechada" a formação dos policiais no Brasil, sem a participação de profissionais de outras áreas, "favorecendo amplamente a difusão de valores e padrões de conduta", formando uma determinada visão de mundo baseada em preconceitos, crenças e estereótipos que são utilizadas como categorias explicativas do mundo e ativadas no exercício da sua atividade profissional. No caso específico do Brasil, essa visão de mundo, segundo identificou a autora, seria formada por características como: clara divisão do mundo social em "nós/eles", atitude constante de suspeita, isolamento social e a solidariedade em grupo, traduzida no forte corporativismo, formação de subculturas de cada carreira ou posição hierárquica, relação distante com o publico e a afirmação do etos guerreiro voltado a realizar a missão de combate ao crime. Esse processo histórico de formação da cultura policial acima descrito teria por consequência, segundo Bueno entre outros fatos, padrões de conduta truculentos e arbitrários que foram reforçados durante a Ditadura Militar, no qual a promulgação da nova Constituição não significou profundas mudanças. Como já indicado acima, as normas escritas possuem pouca capacidade de modificar o etos policial.

Outra linha de abordagem parte das relações de sociabilidade e a aderência ao processo de consolidação do monopólio legítimo da violência pelo estado, através da consolidação ou degeneração de uma cultura de civilidade por parte da sociedade. Nessa perspectiva, Zaluar defende que no Brasil, além do monopólio legítimo do uso da violência nunca ter se efetivado, a partir do final dos anos 1960, deu-se "um retrocesso nos códigos de conduta e autocontrole individual das emoções mais primitivas em razão da aposta na repressão violenta a qualquer oposição e à militarização das funções administrativas" do estado brasileiro, além do enfraquecimento do papel da política. Essa atitude autoritária do estado teria provocado uma descrença nos jogos de negociação, do diálogo e do conflito limitado moralmente. Além disso, a facilidade de acesso às armas e o tráfico de certas substâncias criaram organizações subterrâneas, que passaram a abalar ainda mais o monopólio legítimo da força. Isso produziu um ambiente no qual o etos social passou a ir na direção contrária de uma cultura da civilidade, com a estruturação de códigos e práticas sociais baseadas na violência, despertando especialmente na juventude o etos do guerreiro, e que passou a ser potencializada por uma reação cada vez mais desmedida por parte do estado. 
Em relação a esse processo de acumulação social da violência, Misse vai descrever como, no caso brasileiro, o fortalecimento da capacidade do estado em normalizar as relações sociais, por meio da sujeição criminal, serviu para consolidar uma organização social desigual, onde negros e descendentes pobres de imigrantes foram associados a grupos sempre suspeitos e tendentes ao crime, os quais passaram a produzir uma forma própria de identidade em resposta a esse processo de "presunção (preventiva) de culpabilidade". Assim, segundo o autor, desde os anos 30, conforme o estado brasileiro foi se consolidando, a sujeição criminal foi fortalecendo e cristalizando esse processo de exclusão, o que produziu em resposta a formação de identidades coletivas associadas ao crime, começando a alimentar uma espiral que resultaria no quadro de violência que emergiu a partir dos anos 80 no país.

Como se vê, tratam-se de abordagens complexas e abertas, multicausais, como a própria realidade contemporânea, mas com a capacidade de superar a fragmentação paralisante que acomete a pós-modernidade e de assumir a responsabilidade de propor caminhos alternativos, enfrentando diretamente duas falas recorrentes do atual discurso sobre a violência no país: a) a de que não existe nenhuma forma diferente de agir do que a atual e de b) que não há nada que se possa fazer, pois a violência seria uma consequência natural dos nossos tempos. Mais do que qualificar o debate acadêmico e apesar de partirem de diversos pontos diferentes e percorrem caminhos distintos, todos os textos convergem para um mesmo ponto em comum, às vezes expressos de forma mais ou menos explícita: a necessidade urgente de uma nova política de segurança, em que a atuação do estado tenha efetiva capacidade de intervir no fenômeno social, mas não de forma a reproduzir e amplificar diversas patologias sociais, encravadas na formação histórica de nosso país, mas capaz de propor novas formas de sociabilidade, instauradas na capacidade de diálogo e reconhecimento.

A profunda dimensão crítica desses textos é defender que o caminho para se superar a violência no Brasil hoje é modificar a própria forma de estrutura das relações sociais historicamente construídas no Brasil, indo, portanto, de encontro àquelas concepções tão recorrentes que reforçam o retorno ao passado, a uma ordem social verticalizada e estruturada por diferenças de gênero, raça ou classe, ancorada num estado autoritário, sem transparência e numa estrutura jurídica de fracas garantias. Pelo contrário, o prognóstico apresentado é que apenas modificando essa ordem social poderemos construir uma sociedade que afirme no cotidiano das relações e nas relações entre estado e sociedade os ideais democráticos, com a consolidação de garantias jurídicas e com a apropriação do estado pela sociedade, através de mecanismos de 
controle e transparência. Apesar de perceberem tendências e padrões tão profundamente enraizados e cristalizados nas práticas individuais e sociais, nenhuma das reflexões abre mão de uma compreensão sobre o papel que os sujeitos sociais possuem nessa realidade, o espaço para a disponibilidade de suas ações e a possibilidade de modificarem sua realidade e os rumos de sua história. Aliás, do contrário, para que mesmo serviria despender energia na tentativa de compreensão da realidade social, se essa não estivesse disponível aos seus atores?

É nesse sentido que Muniz e Proença Júnior, propõem a construção de um novo consenso sobre a definição do mandado policial, como forma de modificação do atual ethos dos profissionais de segurança pública brasileiros. Para eles, deve-se partir de um conceito sobre "o que a polícia é" que seja efetivamente baseado na realidade, e que seja mais abrangente do que os casos particulares e menos genérica do que um conceito abstrato. Para isso, buscam um conceito relacional, que se foque no uso da força por parte das forças de segurança em relação ao conjunto da sociedade. Dessa forma, a dimensão "o que a sociedade espera que a polícia faça" e a dimensão "o que de fato ela faz" estão interligadas. O mandato policial é a própria autorização social que legitima a ação policial e a qual ela deve sempre estar vinculada. Nessa perspectiva, o mandato policial está muito além da verificação dos diversos rituais formais. É na confiança da sociedade em sua polícia e na capacidade dessas em fazer a lei ser cumprida, sem recorrer sempre ao uso da força, que se encontra o critério de verificação da qualidade do trabalho policial. A forma de viabilização do mandato policial assim compreendido vai muito além das práticas punitivas e repressivas do atual etos. Ela depende da criação de espaços e formas de controle e participação social para se viabilizar, induzindo uma espiral positiva entre polícia e comunidade, reforçando o mandato policial e o sistema democrático como um todo.

Esse conceito poderia servir de referência para um processo de modificação da cultura policial e reconstrução da identidade profissional do policial brasileiro, como Poncioni defende e afirma ser possível, ao afirmar que como "uma representação simbólica socialmente construída em um processo sócio-histórico-dinâmico" essa identidade pode sim "adquirir diferentes significados e definições", por iniciativas de educação policial.

Uma definição mais profissional sobre violência policial, como defendido por Bueno, através da utilização de padrões internacionais de uso da força como indicadores sobre o grau de uso abusivo da força policial, também pode ser um passo fundamental para induzir essa modificação. Na medida em que 
os atuais padrões de atuação comecem a ser questionados pela sociedade e se desnude cada vez mais a fragilidade atual do mandato policial, especialmente em relação a determinados segmentos sociais, questionando e modificando inclusive as formas de abordagem do tema por parte da mídia, é possível iniciar a reversão da atual espiral de violência e perda da confiança nas instituições públicas que o Brasil vive.

No "outro lado da moeda" do mandato policial, isto é, nas relações de sociabilidade, Zaluar nos indica que é fundamental levar em conta a "dimensão da sociabilidade já constituída", especialmente a convivência intergeracional, e nas expressões que sobraram da civilidade, como o carnaval, para instituir dinâmicas reconstrutoras dos vínculos sociais baseados na civilidade, especialmente através do estímulo a formação de jovens, desde a socialização infantil na família, para que eles sejam capazes de desenvolver uma flexibilidade moral, capazes de refletir sobre os modelos de conduta disponíveis. Mas essa nova concepção de políticas públicas de segurança e de orientação das instituições policiais pressupõe novos modelos e ferramentas de gestão, que estejam muito mais conectadas com a realidade social do que com tarefas burocráticas ou os registros formais de criminalidade e orientados pelos princípios de gestão de um estado constitucional.

Uma das grandes prioridades nesse novo modelo de gestão passa a ser a mensuração da qualidade da relação entre a polícia e o conjunto da sociedade, em especial dos grupos socialmente mais vulneráveis, e o nível de confiança desses setores nas instituições. Nesse sentido Zilli, Marinho e Silva, apresentam a relevância das pesquisas de vitimização, que vêm sendo cada vez mais utilizado em todo o mundo, mas que no Brasil ainda são pouco difundidas. Outra relevante ferramenta apresentada no livro são os mapeamentos criminais (Figueira), que ao mesmo tempo em que garantem à polícia uma orientação detalhada e qualificada da dinâmica criminal, também é uma importante ferramenta de controle da atividade policial. Essas ferramentas devem ser utilizadas pelas instituições de segurança em processos de avaliação permanentes (Loche, Carbonari, Hoffman e Serrano-Berthet), que efetivamente monitorem e avaliem as ações, técnicas e programas empreendidos de forma transparente para o conjunto da sociedade e como orientação para a tomada de decisões por parte dos gestores. Os autores destacam a importância de se realizar avaliações voltadas a mensurar o efetivo retorno das ações para os grupos beneficiários, através de avaliações de processo, de eficácia, de resultados e de impacto. Neste ponto, os autores destacam a pouca tradição de avaliações das políticas de segurança e a resistência de seus atores em aplicar tais processos no Brasil. 
Como se vê, esse campo de mudança apontado também não resvala para aquela concepção confortável e fixa de mudança, que afirma que tão somente numa nova ordem, totalmente outra, seria possível modificar essas estruturas de poder e os padrões de relacionamento. Até porque, bem se sabe que na experiência histórica tais receitas produziram absolutamente seu inverso. É na realidade social complexa, dinâmica e contraditória do espaço cultural, jurídico-político-institucional do presente histórico, que essas intuições de mudança se propõem a serem experienciadas, escolhendo como referencial da ação transformadora a proposta de que somente por meio do exercício dialógico se pode construir uma organização social mais democrática. Dessa forma se evita a tentação de que os fins projetem uma tal flexibilidade moral sobre a ação presente, a ponto de novamente reforçar práticas violentas sob nova roupagem.

Dito de forma mais direta: é no curso dessa democracia que temos, com seus imensos limites, que se propõe a construir, processualmente, uma democracia mais substancial. Isso não implica, no entanto, em aceitar os limites do protesto impostos por ordem social. É preciso ampliar largamente a compreensão e o próprio exercício da ação contestadora, para que se questione mesmo, e com intensidade, a própria legitimidade do mandato do controle social, afinal estruturas de poder não se modificam por benevolência.

O conhecimento expresso na obra é portanto um saber-poder, um saber que não aceita ser mero espectador de uma realidade em que percebe diversas e profundas patologias, de graves consequências. Não é um conhecimento acadêmico que se esconde atrás dos muros da universidade para admirar suas belas estátuas. Mas também não é um saber que cai na ilusão totalitária de poder reconstruir toda uma realidade. São análises portadoras de alternativas humildes e concretas, mas nem por isso menos ousadas e com grande potencial de transformação das práticas individuais e institucionais. As pesquisas que partem das relações intersubjetivas entre indivíduos, estes e as instituições, em dimensões histórico-culturais-psicológicas complexas podem ajudar o Brasil a construir novos caminhos para a superação do atual quadro de violência. É preciso ir muito além das propostas que enxergam no uso do direito penal a ferramenta para "reconstruir" as sociabilidades no Brasil. Na verdade as políticas públicas de segurança precisam colaborar para a desconstrução do padrão de sociabilidade vertical e excludente que se estabeleceu na formação histórica do Brasil e que sempre se utilizou das instituições de segurança para a sua manutenção e do discurso do medo para sua legitimação.

O caminho para o país superar a violência está na formulação de políticas públicas de segurança com o potencial de desvelar e superar determinadas 
racionalidades vinculadas a "uma rede de dominação, de vários tipos" e que se manifestam como uma "rotina de violência" que "dilacera a cidadania" e seja capaz de fomentar práticas sociais instauradoras, "orientadas pela não violência e pela negociação dos conflitos" (Tavares dos Santos). Não será o sistema de crenças que nos trouxe até essa dura realidade de sermos o país responsável por $11 \%$ dos homicídios do mundo, que conseguirá modificar essa realidade. Precisamos ampliar nossa capacidade de refletir criticamente sobre a realidade social e a forma de intervenção do estado. Mais do que velhas certezas, precisamos de novas perguntas.

Talvez nenhum outro tema seja tão relevante para o futuro da democracia política e social no Brasil, quanto a segurança pública. As alternativas existem e elas saltam das páginas dessa obra, clamando para que sejam arrancadas do papel e devolvidas a realidade de onde saíram, não mais como tragédia, mas como política pública renovada e transformadora.

Recebido em: 24 dez. 2014

Aprovado em: 30 jan. 2015

Autor correspondente:

Alberto L. Kopittke

Rua Itaboraí, 139/201

90670-030, Porto Alegre, RS 